\title{
A Review on Zero Energy Building Using LED DC Luminaries and Daylight Harvesting Systems
}

\author{
Gaurav Patil \\ M.Tech Scholar \\ Department of Energy Technology \\ Truba Institute of Engineering \& Information \\ Technology \\ Bhopal, M.P., India \\ gauravpatil1104@yahoo.in
}

\author{
Shravan Vishwakarma \\ Asst. Professor \\ Department of Energy Technology \\ Truba Institute of Engineering \& Information \\ Technology \\ Bhopal, M.P., India
}

\begin{abstract}
The construction sector currently accounts for about a third of global energy consumption and a large part of this consumption is directly attributed to the design and construction of buildings. A wide range of measures has been adopted and implemented to actively promote better energy efficiency in buildings, including the ZEB (Zero Energy Building) concept, which is a realistic solution for reducing $\mathrm{CO}_{2}$ emissions.The zero-energy construction is discussed in this article. Energy resources have been described. NZEB's goal is not only to minimize the building's energy consumption by using passive design methods but also to design a building that reconciles energy needs with active techniques and renewable technologies.
\end{abstract}

Keywords: building energy efficiency, NZEB, light control system, optical fibers.

\section{INTRODUCTION}

According to current estimates, the building industry accounts for approximately one-third of total global primary energy usage, with a significant portion of this consumption being related primarily to building planning and manufacturing [1]. To actively promote improved energy performance of buildings, a wide range of policies and programmes have been adopted and implemented. One such policy is the net zero energy building (NZEB) concept, which is a reasonable choice for the reduction of greenhouse gas (GHG) emissions. It is also a potential method of reducing the amount of energy consumed by buildings, which can help to relieve the present global energy concerns of growing prices, climate change, and supply security [2], which are all being faced by the world. A reduction in the electricity consumption for electricity generation is implied by the NZEB, with the reduction in demand being met on an annualized basis by renewable power sources, which may be incorporated into the building design or delivered, for instance, as component of a collective green energy supply systems. When there are no renewable energy sources available, the grid will be used to provide electrical energy, but when there is excess power production, the buildings will send electricity back to the grid, in many cases selling this transferred power to the regional utilities provider throughout a Feed-In Tariff programme. While the goal of NZEBs is to improving energy efficiency through passive design methods, they also aim to create a structure that optimizes energy demand with active approaches and alternative energies. Identification of individual energy end uses such as heating and cooling of space, ventilation, water heating lighting, refrigeration systems and other systems such as mechanical and computer systems is the first step in determining a building's energy demand [3]. An important first step in enhancing building performance is to ensure that all the components listed above are as efficient as possible. Building efficiency is stated as the ratio of the building's energy consumption to the building's energy use.

\section{LITERATURE REVIEW}

L.T.Doulos et al. [4] Lighting technologies (AC and DC) as well as two daylight harvesting systems are examined in the article, which is based on a typical classroom in a Greek public school. To compute energy savings and light adequacy, the first employs one photo sensor per luminaire, while the second uses one sensor per control zone. Measurement of the dimming curves of the DC LEDs was done in conjunction with the photo sensor's installed power. Lighting primary energy usage can be lowered from the current $90.5 \mathrm{kWhp} / \mathrm{m} 2$ to $0.55 \mathrm{~kW} \mathrm{hp} / \mathrm{m} 2$.

When the DZ is calculated using the geometrical method, the extent of the DZ varies between 30 and 100 percent of the total area in each office; when daylight factors are used, the extent varies between 50 and 100 percent; and the extent of the DZ is calculated using dynamic daylight metrics, the extent of the DZ is between 30 and 60 percent of the total area in each office. Based on the calculating method, the geometry of the room, and the Window to Floor Area, the 
number of luminaires within the DZ can vary between 30 and 100 percent in the same space.

Suk-Kyung Kim et al. [6] A future research agenda is discussed, with a particular emphasis on the necessity for post-occupancy studies that should include current occupants in order to preserve energy-efficient accommodation performances. It is also necessary to construct an integrated strategy for zero-energy houses that incorporates the design, development, and maintenance components of the buildings in order to encourage an energy-efficient and ecologically responsible housing alternative for a variety of residential categories.

Sagar E. Shinde et al. [7] present their findings in this paper, which includes a biogas plant, natural ventilation, day light, night purge, radiant cooling system, green wall, solar chimney, exhaust fan, rain water harvesting, bore recharge, shape of the and energy according to sunlight and wind, hollow concrete blocks with wood blocks in the inner hollow portion, use of biological organic waste as fertilisers, use of green cement and the production of short farms.

\section{ZERo ENERGY BUILDINGS (ZEB)}

Buildings with zero energy consumption can be defined in a variety of ways, based on their location and the metric being used. Depending on the objectives of the study as well as the beliefs of the designing group and the homeowner, other definitions can be appropriate. Building owners, for example, are typically concerned about electricity prices. National energy numbers are of concern to organisations such as the DOE (Department of Energy), which is usually more focused in main or source electricity. In order to comply with energy code standards, a building designer may be interested in the site's energy use. The reduction of emissions may also be of interest to those who are concerned about pollution caused by power plants and the burning of fossil fuels. net zero source energy, net zero energy costs, net zero energy emissions and Net zero site energy, are the four most commonly used definitions for net zero energy.

There are several distinct renewable energy sources that can be used in each definition, and each definition relies on the grid for net use accounting. The concepts are applicable to structures that are not based on a grid. Whenever possible, supply-side option 2 should be used, as long as the resource will be available for the entire life span of the building. [8] Purchase of sustainable power from off-site resources, or, in the instance of a negligible building, the purchase of emission credits, can be used to attain off-site ZEB status. Specifically, the following definitions pertain to ZEBs that make advantage of supply-side choices that are readily available on site in order to satisfy DOE's ZEB research requirements.
Off-site ZEBs are designated as such for ZEBs that have a portion of their renewable generation supplied by sources other than the building's on-site generation.

\section{A. Net Zero Site Energy.}

When all of the energy produced and consumed at the site is taken into consideration, a ZEB site creates at least quite so much power as it consumes in a year.

Site energy consumption is zero. When all of the energy produced and consumed at the site is taken into consideration, a ZEB site produces at least as much energy as it consumes in a year.

\section{B. Net Zero Source Energy.}

When all is said and done, a ZEB source generates at least as much energy as it consumes in a year. The principal energy that is used to generate and deliver electricity to a location is referred to as the source energy. Imported and exported energy are multiplied by the relevant site-to-source conversion multipliers to arrive at the total source energy of a building.

\section{Net Zero Energy Costs.}

It's important to note that in a cost ZEB, a utility must give at least as much money back to the homeowner as it charges for the energy systems and power it provides.

\section{Net Zero Energy Emissions.}

Buildings with zero emissions generate as much energy from emission-free renewable sources as they consume.

\section{NEAR ZERo-EnERgy BUILDingS}

An NZEB-designated facility might not be able to maintain a net-zero energy status in operation every year. Weather, building condition, operational conditions are all factors that can cause a building to slip into the near NZEB category in any given year. During unusual weather years with aboveaverage heating and cooling loads and below-average solar and wind resources, a well-functioning NZEB may also become a near NZEB. Every year, utility bills or submetering, or a combination of the two, should be used to assess the NZEB status.

\section{ENERGY RESOURCES}

\section{A. Non-Renewable Energy Resources}

A non-renewable resource (also known as a finite resource) is one that cannot be replenished at a phenomenal pace. Nonrenewable energy resources include fossil fuels such as petroleum, natural gas and coal.

\section{B. Renewable Energy Resources}


Renewable Energy Resources are a type of energy that can be used repeatedly without posing a significant danger to the environment. Renewable Energy Resources include sunlight, wind, rain, tidal energy, and geothermal heat. The emphasis is on achieving a Net Zero building by utilising Renewable Energy Resources rather than Non-Renewable Energy Resources. To make the building net zero, we can employ solar, wind, and tidal energy, among other options. Due to a lack of technology, we are unable to utilise geothermal energy on a large scale. When the air velocity is really high, we can use wind energy. It only works in open places. Solar energy is the most extensively used renewable energy source. Solar Panels can be used as solar thermal heaters and photovoltaic cells other applications.

\section{Connections of PV Solar Modules}

There two types of connections which are given below:

Grid Connection : A solar power system that is linked to the electric grid, also known as a grid-connected PV power system. Solar panels, one or more inverters, a power conditioning unit, and grid connection equipment are all components of a grid-connected PV system. When on-site energy generation, on the other hand, exceeds the building's energy needs, the excess power should indeed be transferred back towards the utility grid, if legal. Later periods of surplus demand are compensated by the extra energy output, leading to a net power usage of zero. Grid connection is normally required to enable the Net Zero Energy balance due to present technology and cost limits connected with energy storage.

Off Grid Connection: When your solar photovoltaic systems is not linked to the grid system and you produce your own electricity using solar, wind, generators, and other methods, you are said to be off grid photovoltaic. A battery bank will typically be included in these ways to collect electricity for later usage.

\section{OFF-Grid NeT-ZERo ENERGY}

Buildings Because the present generation of energy storage technology is limited, achieving a NZEB without the grid is extremely challenging. Off-grid buildings, despite their electrical energy independence, space heating, water heating, and backup generators, rely on outside energy sources for cooking such as propane and other fuels. Off-grid buildings are unable to feed excess energy production back into the grid to offset other energy consumption. As a result, renewable energy output must be significantly increased. Excess generated energy cannot be utilized in many instances (particularly during the summer). It is, nevertheless, feasible to create a grid-independent NZEB. Any backup energy demands, such as biodiesel or wood pellets would have to be met this way. Because no fossil fuels or net yearly energy balances are required or consumed, an off-grid building that consumes no fossil fuels might be deemed a pure NZEB.

\section{VII.ZERO ENERGy BEyOND A Single BuILDING}

Extending the border of NZEBs to groupings of buildings, universities, villages, towns, bases, or cities becomes viable as the concept of NZEBs becomes more technically and economically realistic. Zero-energy campuses, neighborhoods, and communities are a viable alternative to solitary NZEBs. Pushing the total energy limit beyond just a single structure tackles the growth of towns, neighborhoods, and institutions that produce RE for a group of buildings, but the power does not necessary actually link to a building's utility meter. Citizen alternative fuels that are linked to the grids or a local heating and air - conditioning system might be possible here. Instead of having RE generated on (or in addition to) each building in a major organization or neighborhood, it is more premium and efficient to have it generated at a central point inside the campuses or locality. It is possible to reduce the cost per kilowatt of generation capacity by using larger, central systems. Larger, central systems can be more efficiently optimised and cost less per kilowatt of generation capacity with community-scale systems since they offer economies of scale and a single point of maintenance for all maintenance. Community-based RE systems, on the other hand, suffer transmission and distribution losses when providing RE to a building [9]. When a district distribution system is used instead of a building-based RE generation system, inefficiencies and costs emerge from the use of distribution pipelines and wiring as well as pumping and distribution transformer losses.

\section{DAYLIGHT}

Daylight is the light from the sun and in the sky during the day, it is the visible part of the electromagnetic filed reaching the Earth from the solar radiation. Its main feature is that it changes constantly both because of sun position changes in the sky and because of weather local climate conditions change. In particular this last factor can highly and unpredictably affect solar radiation at the surface due to presence of clouds of variable thickness. Moreover daylight is also depending on the geographic position in which the observer is, in fact the temperature colour of the light and its intensity highly depend on the angle of incidence of solar beams on the Earth' surface [10]. This is why even though sunlight, one of the two components of daylight, refers to parallel light beams coming from the Sun, when those beams reach the atmosphere they are partly scattered through the different layers surrounding our planet. Another variable cause of daylight is the inconstant solar radiation, even 
though hours of daylight and the diurnal variation are very predictable at any location and season [11]. Depending on season, characterized by a relatively homogeneous height of the Sun in the sky, different meteorological sky conditions (clear sky, mixed sky and overcast sky) can give similar, or very different, daylight levels:

- From January to mid-February and from mid-November to December: daylight level on the working plane is the same except for overcast sky condition;

- During the winter period clear and mixed days have similar daylight levels and overcast sky are significantly lower;

- In spring mixed and overcast days give similar daylight levels and clear sky are significantly lower;

However these rules are not valid for the colour temperature and daylight distribution on different surfaces than the working plan. In a narrower perspective daylight reaching a limited area on the ground is influenced by the topographical conformation and presence of vegetation in a non-atrophied region and by the surrounding buildings in a city or small town. Focusing on indoors daylight highly depends on exposition of the building itself, planking level of a room, windows shape and position, presence and colour of blinds.

\section{OPTICAL FIBER}

Optical fibers are well knownas fiberscopes for imaging applications and as light guides for a wide range of nonimaging applications. In the latter context, they can also be used for day lighting: a solar lighting system based on plastic optical fibers was in development at Oak Ridge National Laboratory in 2004; the system was installed at the American Museum of Science and Energy, Tennessee, USA, in 2005, and brought to market the same year by the company Sunlight Direct. However, this system was taken off the market in 2009. Optical fibers are also used in the Bjork system sold by Parans Solar Lighting AB. The optic fibers in this system are made of PMMA (PolyMethylMethAcrylate) and sheathed with Megolon, a halogen-free thermoplastic resin. A system such as this, however, is quite expensive [12]. In view of the usually small diameter of the fibers, an efficient day lighting set-up requires a parabolic collector to track the sun and concentrate its light. Optical fibers intended for light transport need to propagate as much light as possible within the core; in contrast, optical fibers intended for light distribution are designed to let part of the light leak through their cladding.

Fibre optics in lighting design

Fibre optics as mentioned previously, are a new technology that is growing quickly. If it is possible to carry artificial light through fibre optics, it should be possible to transport daylight through fibre optics into buildings. Then the integration of daylight and artificial light would lead to reductions on the artificial lighting system use and hence save energy and reduce environmental pollution.

\section{COnClusion}

Building a zero-energy home will be done with the goal of making "eco-friendly human comfort" a priority. The global population has grown tremendously, which has led to an increase in energy consumption. Structures account for approximately $40 \%$ of the world's total energy consumption. We could deplete all natural resources within a few years if we continue on this path of energy use and population growth projections, with few new sources of fossil fuels. Design, construction, and operation of both new and existing buildings can reduce environmental impact by incorporating energy-efficient technologies. In the future, overall energy structures are expected to be more common, allowing for more efficient and environmentally friendly energy systems. Building zero-energy homes is a financially, health-wise, and sustainable in the long responsible idea that even more people need to incorporate into their building practises. For future energy conservation, fibre lighting and solar power are essential.

\section{REFERENCES}

[1] J. Marszal, P. Heiselberg, J. S. Bourrelle et al., "Zero Energy Building - a review of definitions and calculation methodologies," Energy and Buildings, vol. 43, no. 4, pp. 971-979, 2011.

[2] P. Torcellini, S. Pless, and M. Deru, "Zero energy buildings: a critical look at the definition," in Proceedings of the ACEEE Summer Study on Energy Efficiency in Buildings, Pacific Grove, Calif, USA, August 2006.

[3] E. Musall, T. Weiss, A. Lenoir, K. Voss, F. Garde, and M. Donn, "Net zero energy solar buildings: an overview and analysis on worldwide building projects," in Proceedings of the EuroSun Conference, Graz, Austria, 2010.

[4] L.T.Doulos, A.Kontadakis "Minimizing energy consumption for artificial lighting in a typical classroom of a Hellenic public school aiming for near Zero Energy Building using LED DC luminaires and daylight harvesting systems" Energy and Buildings, Volume 194, Pages 201-217, 1 July 2019.

[5] K. Mantzourani, L.T. Doulos "The effect of the daylight zone on lighting energy savings" IOP Conference Series: Earth and Environmental Science, January 2020.

[6] Suk-Kyung Kim, sung-jin le "Zero-energy home development in Korea: energy-efficient and environmentally friendly design features and future directions" Journal Housing and Society Volume 42, issue 3, 2015.

[7] Sagar E. Shinde, Anushka B. Chavan "Implementation of Zero Energy Building” IJARSE, vol. 6, issue 3, march 2017.

[8] Paul Torcellini, Shanti Pless, "Zero Energy Buildings: A Critical Look at the Definition" Conference: 2006 ACEEE Summer Study on Energy Efficiency in Buildings, At Asilomar, Pacific Grove, California, Vol. 3, pp. $417-428$.

[9] Danny H.W. Li, Liu Yang "Zero energy buildings and sustainable development implications e A review” Energy, pp. 1-10, 2013. 
[10] Allen Jong-WoeiWhang, Tsai-HsienYang "A Review of Daylighting System: For Prototype Systems Performance and Development" energies, vol. 12, issue 15, 2019.

[11] Mushtaha, E.; Kana'an, B.A.; Al-Jawazneh, R.A.; Hammad, R.S. Effect of using different light pipe parameters on the daylight quality in buildings: The case of Jordan. Int. J. Green Energy 2016, 13, 15901598.

[12] R. R. Date, S. M. Shamkuwar, "Daylight Harvesting System: A Review on Light Harvesting Technologies in Commercial Buildings" International Journal of Analytical, Experimental and Finite Element Analysis (IJAEFEA), Issue. 4, Vol. 1, Dec 2014. 